\title{
How the Lives of Neuroradiologists and Neurosurgeons Have Been Changed by COVID-19
}

$\mathbf{T}$ wo months ago, European neuroradiologists and neurosurgeons were planning their respective annual congresses in spring and summer, the best time of year in Europe and the United States. Suddenly an "earthquake" from Asia hit our shores. Italy was one of the first countries to be affected and went on to become one of those paying the highest toll alongside Spain. Country borders were closed, and in Europe, people were ordered to self-isolate at home. In the United States, the mythical McCormick Place, associated with teaching, meeting, and friendship and where the biggest radiology congress in the world has taken place for many years, was turned into a hospital.

Hospitals all over Europe drastically modified their activities. However, leaders of clinical services reacted differently; some, more distant from "the floor," tended to be "behind the curve" as the pandemic quickly evolved and issued orders disconnected from the real situation and, depending on the material capacities, quite similar to what played out at national levels. On the other hand, professional societies like the European Association for Neurosurgical Societies (EANS) provided direction on how to triage nonemergent neurosurgical procedures, ${ }^{1}$ and the EANS President created a dedicated Web page to provide a discussion forum for European neurosurgeons where they could share their experiences about the impact of this on our professional lives, our hospitals, and our work and how we are coping with it. ${ }^{2}$

At our hospital, Geneva University Hospital and Faculty of Medicine in Switzerland, the neuroradiology and neurosurgery services were instructed to only attend to emergencies and patients in oncology. In everyday practice, patients were separated into those with the disease and those without or who were asymptomatic. In certain larger hospitals, the infrastructure permitted dedication of CT or MR imaging machines to patients positive for coronavirus disease 2019 (COVID-19). Given the strict constraints of resources, the neurosurgeons faced a drastic decrease in operations that could be performed, and residents were reassigned to newly established COVID wards. All multidisciplinary conferences were cancelled, except for oncology boards. In the administrative part, teleworking had to be organized. It was recommended that all hospital staff wear masks and use only dedicated hospital clothes, including shoes, as well as practice social distancing and hand washing.

The university was closed; the researchers and students were sent home, and the courses were taught with the help of distancelearning applications. The private lives of doctors and paramedical staff were also disrupted. Many feared that their professional activities were putting their own families at risk, and some colleagues took extreme precautions to avoid contamination. For many colleagues, childcare had to be reorganized because all schools and daycare centers were closed and grandparents were instructed to self-isolate.

Finally, our thoughts are with those colleagues who are absorbing the biggest burden at any moment and colleagues who have perished in this COVID-19 epidemic.

\section{REFERENCES}

1. EANS advice: triaging non-emergent neurosurgical procedures during the COVID-19 outbreak. https://cdn.ymaws.com/www.eans. org/resource/resmgr/documents/corona/eans_advice2020_corona.pdf

2. European Association of Neurosurgical Societies. COVID-19 in Neurosurgery, News, Guidelines and Discussion Forum. https:// www.eans.org/page/covid-19
M.I. Vargas
Division of Neuroradiology

(D)T.R. Meling

Division of Neurosurgery Geneva University Hospital and Faculty of Medicine 